\title{
An Experimental Study on the Thermal Conductivity of Concrete Containing Coal Bottom Ash Aggregate
}

\author{
In-Hwan Yang, Jihun Park and Hoe-Won Jung \\ Kunsan National University, Department of Civil Engineering, Jeonbuk 54150, Kunsan, Republic \\ of Korea, ihyang@kunsan.ac.kr
}

\begin{abstract}
Thermal conductivity plays a significant role in efficient energy usage, especially in the construction field. Low thermal conductivity is preferable because lower thermal conductivity will increase the thermal insulation provided by the concrete and reduce the heating and cooling costs for residential and commercial buildings. To accomplish this goal, porous materials can be considered for use in concrete. Additionally, researchers have had challenges producing high-strength concrete with low thermal conductivity. Therefore, this study aims to investigate the effects of replacing crushed fine aggregates with coal bottom ash (CBA) on the thermal conductivity and mechanical properties of high-strength concrete. The concrete properties, including unit weight, compressive strength, and thermal conductivity, were measured. The experimental results revealed that the thermal conductivity of the CBA concrete decreased as the unit weight of the CBA concrete decreased, and the thermal conductivity also decreased as the compressive strength decreased. Finally, the relationships between the thermal conductivity, unit weight, and compressive strength of the CBA concrete were also examined.
\end{abstract}

Keywords: Coal Bottom Ash, Thermal Conductivity, High-Strength Concrete, Porosity.

\section{Introduction}

Currently, the demand for energy-efficient buildings is increasing to optimize the internal temperature of buildings (Najjar et al., 2019). One of the key factors for optimizing energy efficiency is thermal conductivity. When a building is constructed from materials with higher thermal conductivity, to ensure the internal temperature of the building, a greater amount of energy must be consumed for cooling and heating. To address this issue, materials with low thermal conductivity are recommended during construction. Thus, considering concrete with low thermal conductivity is the most suitable choice.

To produce concrete with low thermal conductivity, Aghdam et al. (2019) carried an experimental study to estimate the effects of carbon nanotubes on the thermal conductivity of steel fiber-reinforced concrete. Their test results indicated that the agglomeration of carbon nanotubes caused a decline in the concrete thermal conductivity. However, the use of carbon nanotubes is expensive, and high-strength concrete is not considered.

Currently, coal-fired thermal power plants create a substantial amount of bottom ash and fly ash. Bottom ash is industrial waste produced at the bottom of coal furnaces. To develop concrete 
with low thermal conductivity for energy efficiency, an experimental study to investigate the effects of partial or total replacement of crushed fine aggregates with coal bottom ash (CBA) on the thermal properties of concrete is vitally necessary.

Therefore, in this experimental study, the thermal conductivity and mechanical properties of high-strength concrete specimens containing 25,50,75, and 100\% replacement of crushed fine aggregates with CBA were investigated at a curing age of 28 days. The compressive strength, unit weight, and thermal conductivity of these specimens were measured. The relationships between the thermal conductivity, unit weight, and compressive strength of the CBA concrete were also examined.

\section{Experimental Program}

\subsection{Materials}
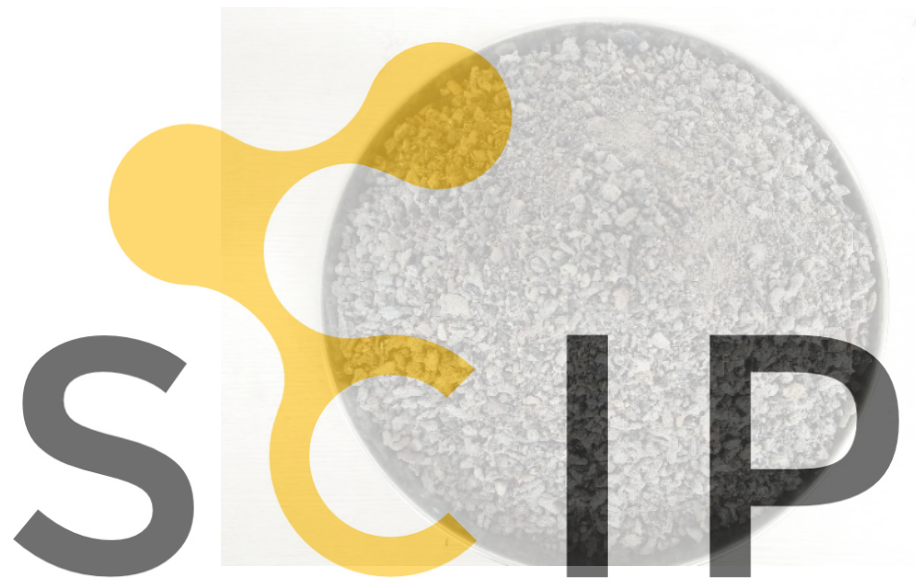

Figure 1. CBA aggregate.

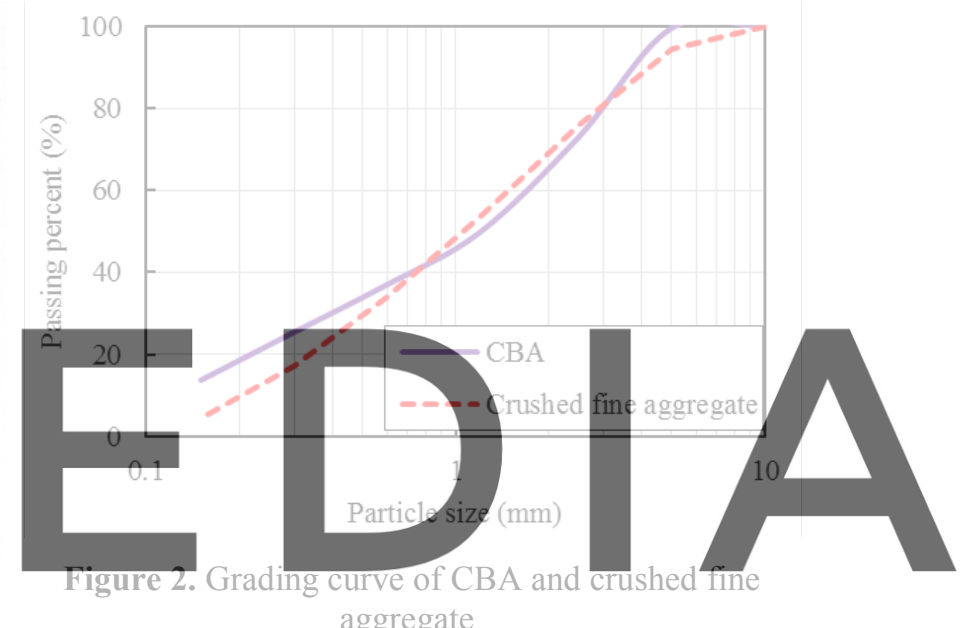

Register for free at https//www.scipedia.com to download the version without the watermark Table 1. Physical properties of fine, coarse and coal bottom ash aggregate.

Fineness

modulus

Water absorption

$(\%)$

Unit weight

$\left(\mathrm{g} / \mathrm{cm}^{3}\right)$

\begin{tabular}{cccc}
\hline $\begin{array}{c}\text { Crushed fine } \\
\text { aggregate }\end{array}$ & 3.17 & 0.69 & 2.60 \\
\hline Coarse aggregate & 6.77 & 1.44 & 2.61 \\
\hline CBA & 3.83 & 6.87 & 1.84
\end{tabular}

The coal bottom ash used in this study was collected from a thermal power plant company in Korea. The CBA aggregate was screened to remove particles greater than $5.0 \mathrm{~mm}$ and to retain the particles greater than $0.15 \mathrm{~mm}$. The CBA used for this study is presented in Figure 1 , and the particle size distribution of the CBA is also presented in Figure 2. The test results of the density and water absorption of the CBA are shown in Table 1. The particle size distribution of the crushed fine aggregates is illustrated in Figure 2. The unit weight, water 
absorption and fineness modulus results of the crushed fine and coarse aggregates are also shown in Table 1.

\subsection{Mix Proportions}

A concrete mix was designed with a target compressive strength of $60 \mathrm{MPa}$ at a curing age of 28 days. The mixing proportions of the control concrete and coal bottom ash concrete are indicated in Table 2. The crushed fine aggregate was replaced with five different volume fractions $(0,25,50,75$, and $100 \%)$ of coal bottom ash in the concrete.

Table 2. Mixing proportions of the coal bottom ash concrete.

\begin{tabular}{|c|c|c|c|c|c|c|c|c|}
\hline \multirow[b]{2}{*}{ Mixtures } & \multirow[b]{2}{*}{$\begin{array}{c}\text { Replacements } \\
\text { of CBA } \\
(\%)\end{array}$} & \multirow[b]{2}{*}{$\mathrm{W} / \mathrm{C}$} & \multirow[b]{2}{*}{ Water } & \multicolumn{5}{|c|}{ Unit content $\left(\mathrm{kg} / \mathrm{m}^{3}\right)$} \\
\hline & & & & $\begin{array}{l}\text { Cement } \\
(\mathrm{OPC})^{\mathrm{a}}\end{array}$ & $\begin{array}{l}\text { Coarse } \\
\text { aggregate }\end{array}$ & $\begin{array}{c}\text { Fine } \\
\text { aggregate }\end{array}$ & $\begin{array}{l}\text { Coal } \\
\text { bottom } \\
\text { ash }\end{array}$ & $\begin{array}{l}\text { HWRA }^{b} \\
(0.6 \% \times \\
\text { cement })\end{array}$ \\
\hline CBA00 & 0 & 0.3 & 178.5 & 595 & 878.5 & 663 & 0 & 3.6 \\
\hline $\mathrm{CBA} 25$ & 25 & 0.3 & 178.5 & 595 & 878.5 & 497.2 & 117.7 & 3.6 \\
\hline CBA50 & 50 & 0.3 & 178.5 & 595 & 878.5 & 331.5 & 235.3 & 3.6 \\
\hline CBA75 & 75 & 0.3 & 178.5 & 595 & 878.5 & 165.7 & 353 & 3.6 \\
\hline CBA100 & 100 & 0.3 & 178.5 & 595 & 878.5 & 0 & 470.7 & 3.6 \\
\hline
\end{tabular}

Cylindrical specimens with dimensions of $100 \mathrm{~mm} \times 200 \mathrm{~mm}$ were cast to measure the unit

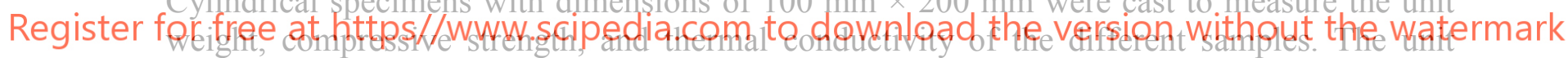

weight, compressive strength, and thermal conductivity of the CBA concrete were measured at a curing age of 28 days. The thermal conductivity of each specimen was measured using a transient plane source (TPS) measurement system, as shown in Figure 3.

\section{Test Results and Discussion}

\subsection{Unit weight}

The unit weight results of the concrete specimens with different coal bottom ash ratios are shown in Figure 4. The figure indicates that the unit weight of the CBA concrete decreased as the replacement of crushed fine aggregate with CBA increased in the concrete. At a curing age of 28 days, the unit weight of the control mixture was $2,370 \mathrm{~kg} / \mathrm{m}^{3}$, whereas the unit weights of the coal bottom ash concrete mixtures CBA25, CBA50, CBA75, and CBA100 were reduced by $2.1,3.2,5.3$, and $7.6 \%$, respectively. The decrease in the unit weight of the CBA concrete mixtures is due to the replacement of coal bottom ash, which is a lighter fine aggregate than crushed fine aggregate, as shown in Table 1. 


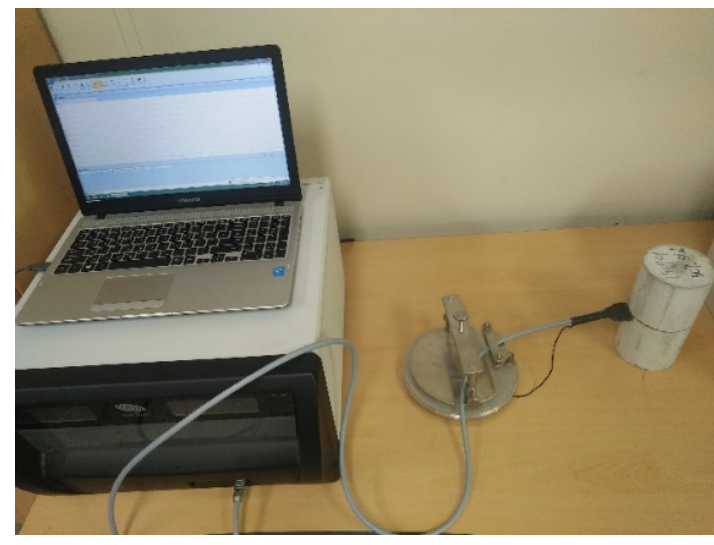

Figure 3. Test setup for thermal conductivity measurements.

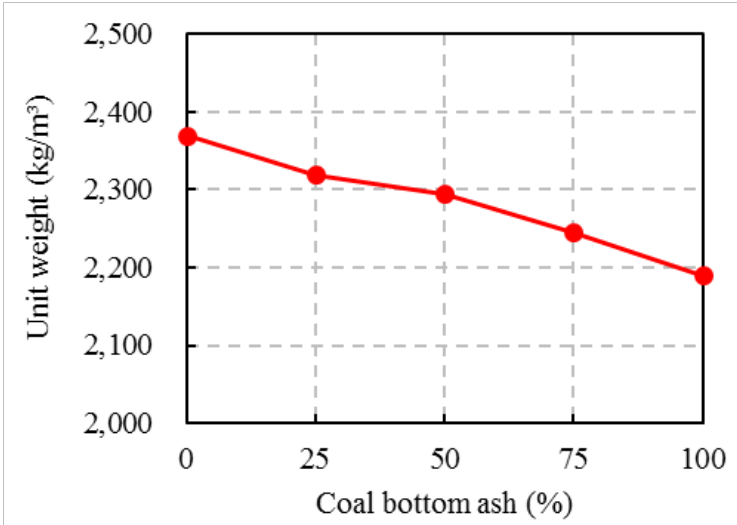

Figure 4. Effect of CBA replacements on unit weight of concrete.

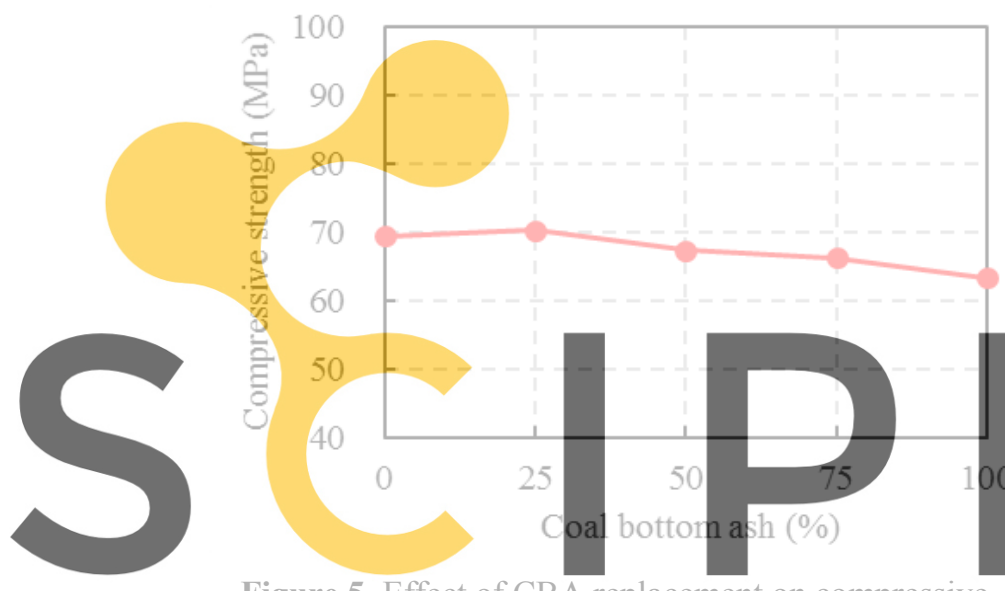

Figure 5. Effect of CBA replacement on compressive

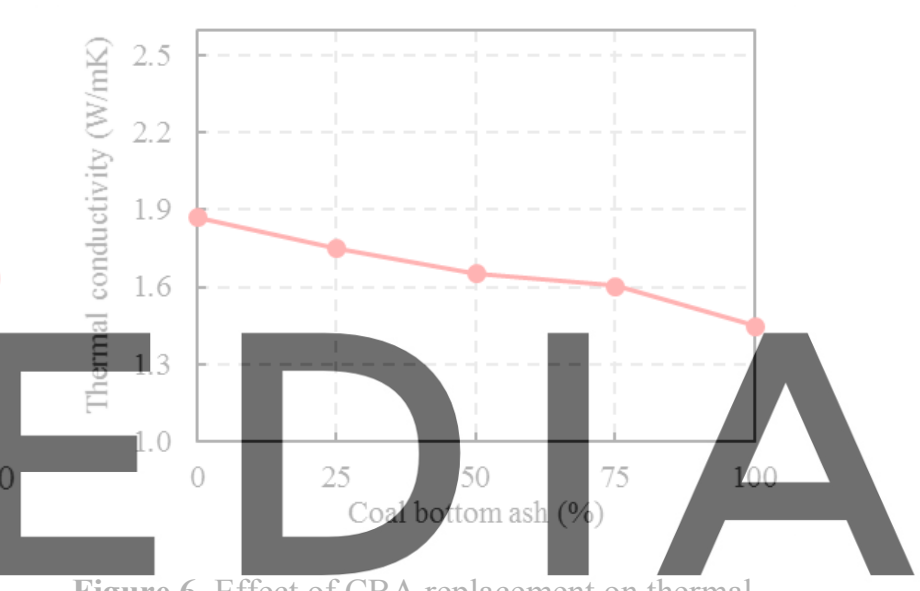

Figure 6. Effect of CBA replacement on thermal

Register for free at https//WwW.scipedia.com to download the version without the watermark

\subsection{Compressive Strength}

The test results of the compressive strength of the concrete specimens with different coal bottom ash contents are summarized in Figure 5. Generally, at a curing age of 28 days, the compressive strength of the CBA mixtures decreased as the CBA replacement increased. The compressive strength of the coal bottom ash concrete mixtures CBA50, CBA75, and CBA100 were 3.0, 4.6, and 8.8\% less than that of the control concrete mixture (69.4 MPa), respectively. However, the compressive strength of the coal bottom ash concrete mixture CBA25 was insubstantially higher $(1.2 \%)$ than that of the control concrete mixture. The compressive strength loss could be explained by the increase in the porosity of the concrete. These porosities cause negative impact on concrete matrix and reduce the compressive strength of the CBA concrete specimens [Singh et al., 2014].

\subsection{Thermal Conductivity}

The thermal conductivities of the concrete specimens with different CBA contents are presented in Figure 6. At a 28-day curing age, the thermal conductivities of the CBA mixtures decreased as the CBA content increased. The thermal conductivities of the CBA concrete 
mixtures CBA25, CBA50, CBA75 and CBA100 were 6.4, 11.7, 14.2, and 22.5\% less than that of the control concrete mixture $(1.87 \mathrm{~W} / \mathrm{m} \cdot \mathrm{K})$, respectively. The thermal conductivity of the CBA concrete with a $100 \%$ CBA content was significantly less than that of the control concrete mixture. It is known that thermal conductivity highly depends on the lightweight aggregate pore structure, the concrete density and the cement paste. Hence, the pore structure was one of the key elements affecting thermal conductivity (Tasdemir et al., 2017). For that reason, the observed decline in thermal conductivity could be explained by the increase in the CBA concrete in the concrete. As the CBA content increased, the total volume of porosity of the concrete increased, and the thermal conductivities of the concrete decreased. Reducing the thermal conductivity would increase the thermal insulation provided by the concrete and reduce the heating and cooling costs for buildings.
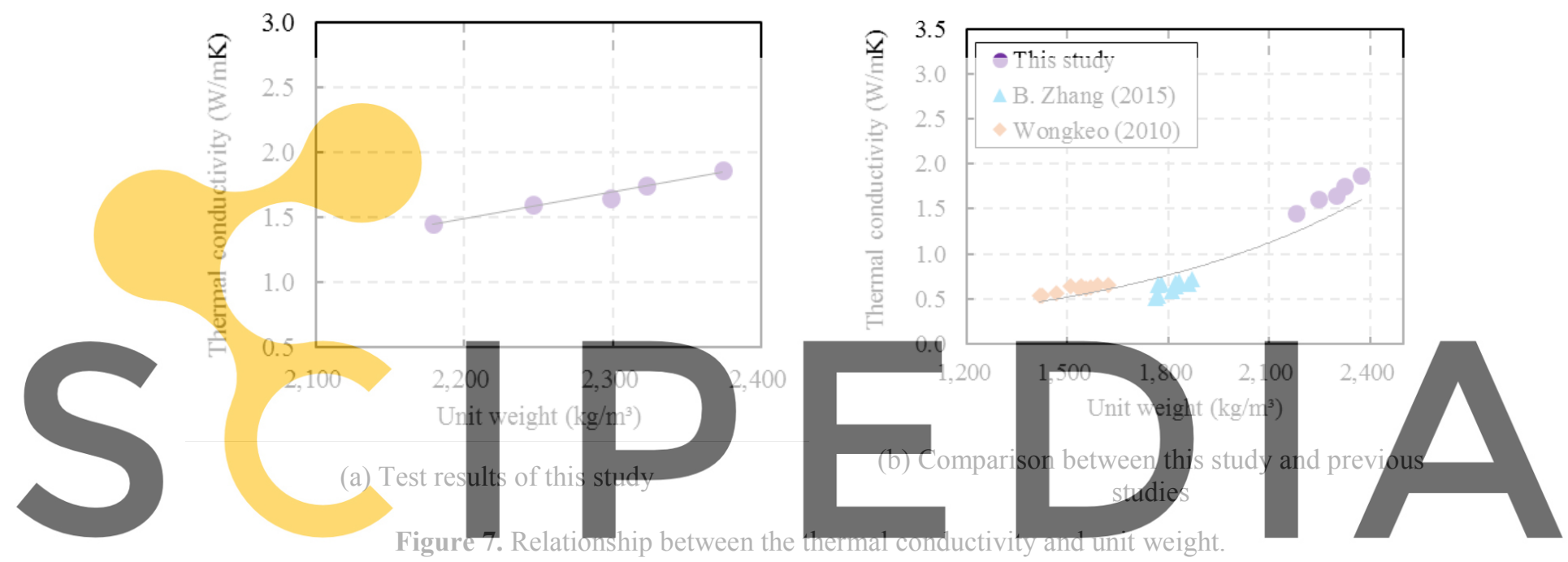

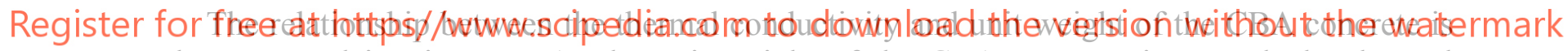
demonstrated in Figure 7. As the unit weight of the CBA concrete increased, the thermal conductivity of the CBA concrete increased. Moreover, the thermal conductivity of the CBA concrete is nearly linearly proportional to the unit weight. Increasing the air voids or lightweight aggregate in concrete is a method to reduce unit weight and thermal conductivity. A similar trend was found when analyzing the test results of Wongkeo et al. (2010) and Zhang et al. (2015), in which the unit weights ranged from 1417 to $1621 \mathrm{~kg} / \mathrm{m}^{3}$ and from 1760 to $1870 \mathrm{~kg} / \mathrm{m}^{3}$, respectively, as shown in Figure 7(b).

The relationship between the thermal conductivity and the compressive strength is demonstrated in Figure 8. This relationship is similar to the relationship between the thermal conductivity and unit weight of the CBA concrete. Additionally, the thermal conductivity has a direct relationship with the compressive strength of the CBA concrete. Figure 8(b) shows a similar trend between the test results in the present research and those of other authors. 


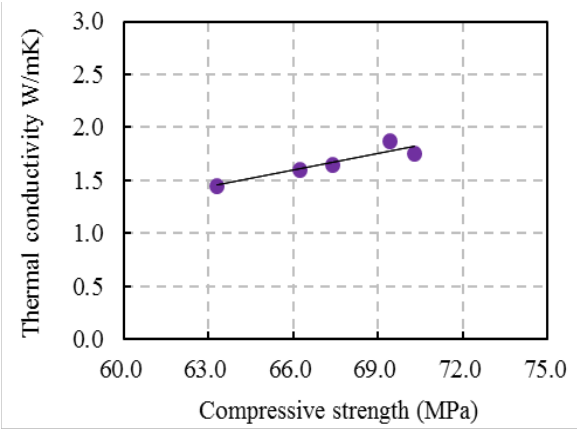

(a) Test results of this study

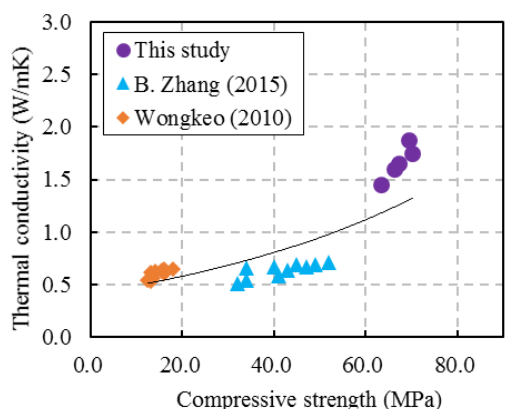

(b) Comparison between this study and previous studies

Figure 8. Relationship between the thermal conductivity and compressive strength.

\section{Conclusions}

In this research, an experimental study was performed on the low thermal conductivity of high-strength concrete specimens with different CBA replacement ratios. The research findings are summarized hereafter:

- The thermal conductivity of the CBA concrete is highly dependent on the porosity in the concrete specimens. For that reason, as the CBA content increased, the thermal conductivity of the CBA concrete decreased gradually. Remarkably, when replacing all the crushed fine aggregate with CBA, the thermal conductivity of the CBA concrete was $22.5 \%$ less than that of the control nixture. As the coal bottom ash content in the CBA concrete strength of the CBA concrete decreased. In particula mixture CBA100 was $8.8 \%$ less than that $\phi$ f the control As the compressive strength of the CBA of the CBA concrete also decreased.

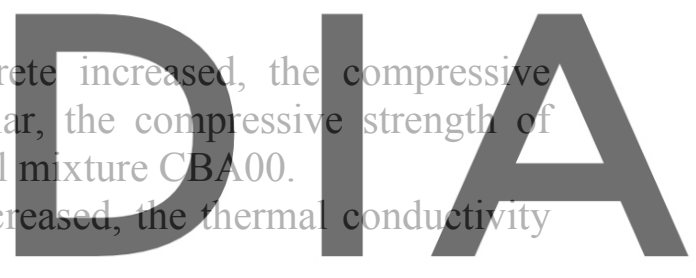

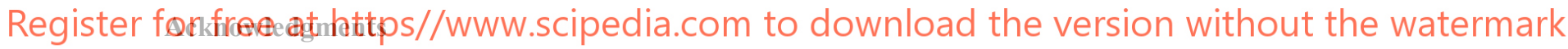

This research was supported by a grant (19CTAP-C151889-01) from the Technology Advancement Research Program (TARP), which was funded by Ministry of Land, Infrastructure and Transport of Korean government.

\section{References}

Aghdam, M.K.H., Mahmoodi, M.J. and Safi, M. (2019). Effect of adding carbon nanotubes on the thermal conductivity of steel fiber-reinforced concrete. Composites Part B, 174, 106972.

Najjar, M., Figueiredo, K., Hammad, A.W.A. and Haddad, A. (2019). Integrated optimization with building information modeling and life cycle assessment for generating energy efficient buildings. Applied Energy, 250, 1366-1382.

Singh, M. and Siddique, R. (2014). Strength properties and micro-structural properties of concrete containing coal bottom ash as partial replacement of fine aggregate. Construction and Building Materials, 50, $246-256$.

Tasdemir, C., Sengul, O. and Tasdemir, M.A. (2017). A comparative study on the thermal conductivities and mechanical properties of lightweight concretes. Energy and Buildings, 151, 469-475.

Wongkeo, W. and Chaipanich, A. (2010). Compressive strength, microstructure and thermal analysis of autoclaved and air cured structural lightweight concrete made with coal bottom ash and silica fume. Materials Science and Engineering A, 527, 3676-3684.

Zhang, B. and Poon, C.S. (2015). Use of furnace bottom ash for producing lightweight aggregate concrete with thermal insulation properties. Journal of Cleaner Production, 99, 94-100. 